\title{
CONTRATO DE APARCERÍA COMO UNA ALTERNATIVA PARA EL SECTOR AGRÍCOLA EN COLOMBIA DEL POSCONFLICTO.
}

\author{
SHARECROPPING CONTRACT AS AN ALTERNATIVE FOR THE COLOMBIAN \\ POSTCONFLICT AGRICULTURAL SECTOR
}

\author{
Grenfell Lozano Guerrero ${ }^{1 *}$ y Luis Fabio Bello Fierro ${ }^{1}$. \\ 1 Universidad Surcolombiana. \\ *Correspondencia del Autor: grenlozguer@hotmail.com
}

\section{RESUMEN.}

El grupo de investigación CYNERGIA a través de su semillero de investigación MERCATORIA I, analiza la historia de la problemática del acceso a la tierra en Colombia. Profundizar la viabilidad del contrato de aparcería como una justa aplicación en Colombia en el periodo del posconflicto. Lo anterior, fue analizado desde el método dogmático, racional y reflexivo, a través de fundamentos históricos, normativos y jurídicos a nivel nacional e internacional. Concluyendo que la aparcería es una opción válida para lograr el acceso y distribución de la tierra, evitando la violencia.

Palabras claves: Aparcería; posconflicto; distribución de la tierra; propietario; historia.

Cómo citar:

Lozano Guerrero, G., \& Bello Fierro, L. (2019) CONTRATO DE APARCERÍA COMO UNA ALTERNATIVA PARA EL SECTOR AGRÍCOLA EN COLOMBIA DEL POSCONFLICTO. Revista de Investigaciones Universidad del Quindío. Vol 31, pp. 26-40. 


\begin{abstract}
The CYNERGIA research group, through its hotbed MERCATORIA I, analyzed the history of the problem of access to land in Colombia. To increase the sharecropping contract appears as a just application for the Colombia in the post-conflict period in Colombia. This conclusion arrived after application of the dogmatic, rational and reflective method, for the historical, normative and legal foundations at the national and international level. We conclude that sharecropping is a valid option to achieve access and distribution of land, avoiding violence.
\end{abstract}

Keywods: Sharecropping; Postconflict; Distribution of land; Owner; History.

\section{INTRODUCCIÓN}

El contrato de aparcería, "del latín apartiarius "ir a parte"”, (Dotta Salgueiro, 2003, p. 3), se ubica como una solución a las necesidades del sector rural, enfrentando las viejas figuras jurídicas como el feudalismo o el colonialismo, y así impulsando alianzas personales entre socios y no entre jefes con empleados ni el de arrendatarios con arrendadores. Esos lazos de colaboración e inversión generarían seguridad y confianza para laborar en las tierras rurales que en la actualidad por distintos motivos económicos, sociales o políticos están abandonadas y sin ningún resultado oneroso para el país.

Lastimosamente Colombia desde comienzos del siglo XX ha dejado a un lado el uso de esta figura jurídica de la aparcería y por lo tanto ha generado mayor disputa entre los que tienen las tierras y los que la buscan. Por ello, para salvaguardar el derecho a la propiedad privada que tiene protección constitucional en su artículo 58 y otorgar una oportunidad progresiva para los que no la tienen, es necesario volver a replicar el contrato de aparcería que a la vez generaría una ayuda para la satisfacción de las necesidades alimentarias de la población más desamparadas y evitar otros conflictos sociales.

La gran importancia de esta institución jurídica, es el impulso de principios contractuales como el de lealtad, buena fe, consensualidad, autonomía y la voluntad privada, confianza, de cargas y el de equilibrio patrimonial. Igualmente tiene una misión social con el campo colombiano al generar trabajo, productividad del suelo y del capital humano, seguridad y el uso del ahorro para prevenir desastres. Del mismo los que no tienen tierras, puedan comenzar a trabajar como aparceros, luego puedan ahorrar y tomar alguna en arriendo o mejor aún lograr la compraventa de alguna donde la intervención del Estado para su obtención puede ser determinante.

EI interés social del contrato de aparcería radica en el hecho de que tal institución jurídica constituye una excelente escuela en que los braceros agrícolas pueden aprender a administrar una pequeña explotación, bajo la tutela del propietario, para que más adelante, cuando se hayan capacitado y hecho sus pequeños ahorros, puedan pensar en tomar alguna finca en arriendo y aspirar, por último, a ser propietarios de las tierras que labren. Claro está que, para que esto se realice y el contrato de aparcería cumpla la importante misión social que le está reservada, se precisa que los propietarios se interesen por sus fincas, que los aparceros sean honrados y trabajadores y que las condiciones que se pacten en el contrato sean justas. (Zulueta, M. 1949, p.3)

La presente investigación se enfoca en el estudio del contrato de aparcería con la Ley 06 de 1975 y analizando la normatividad anterior, en sus cambios y contextos históricos. En primer lugar, determinar la naturaleza jurídica del contrato de aparcería y su respectiva clasificación. Luego resaltar los hechos históricos y jurídicos importantes del sector agrario que ha tenido Colombia desde los tiempos remotos de la colonia.

Así mismo, entra a determinar los retos que ha asumido el Gobierno Nacional para el sector agrario luego de la firma y acuerdo de paz con el grupo armado de las FARC en el año 2016. Con 
ello establecer las principales necesidades actuales que viven los campesinos, el fenómeno del desplazamiento interno, los cambios industriales $\mathrm{y}$ los intentos que se han hecho en su favor.

Basados en todo el proceso histórico y jurídico de las tierras y la aparcería en Colombia, el problema jurídico de la presente investigación será: ¿Es el contrato de aparcería una alternativa para el uso y producción de la tierra en Colombia en el posconflicto?

Por lo tanto, se demuestra que este contrato civil tiene más beneficios y ventajas para disminuir los problemas de desigualdad rural y promover el emprendimiento entre los que tienen los recursos económicos e industriales, es decir los propietarios y los que darían los conocimientos técnicos, la mano de obra y demás servicios quien sería el aparcero, para la formación de una sociedad buscando el lucro y a la vez asumiendo las pérdidas en su conjunto.

La presente investigación se fundamentó principalmente en indagar sobre el contrato de aparcería y en exponerlo como una forma de mitigar el conflicto por el acceso a la tierra en Colombia en la etapa del posconflicto. Por lo anterior, sus objetivos específicos giran en torno a estudiar las ventajas y desventajas que trae el contrato de aparcería y determinar su eficacia y estructura jurídica; identificar el contexto histórico y la normatividad pertinente; acudir a las instituciones del sector agrario para que brinden información sobre el contrato de aparcería; servir de ayuda y asesoría a sectores campesinos de la región surcolombiana sobre el uso del contrato de aparcería.

En base al tema principal y los objetivos del presente proyecto de investigación, se considera necesario acudir al método dogmático, racional y reflexivo, porque se buscará llegar a la objetividad en un tema que debe ser una alternativa para la resolución de la problemática en el sector agrario colombiano. Por ello las conclusiones dadas por este proyecto se entrelazan por unas razones válidas y argumentadas en el reconocimiento del beneficio del contrato.

Utilizando los elementos jurídicos necesarios, aunque es precaria la información sobre este contrato, es desde lo político, histórico y jurídico donde se brindarán elementos suficientes para determinar lo válido del contrato en nuestro sector agrario. La normatividad colombiana que reglamente o determine el contrato de aparcería como es la Ley 6 de 1975 y la demás pertinente. Al igual, que los precedentes histórico-normativos que hablen sobre intenciones de reforma agraria y las de regulación de la tierra.

Para recolectar la información es necesario acudir a la doctrina nacional e internacional frente al uso de la aparcería para así enfrentar los posibles problemas que arroje el impulso nuevamente de este contrato en el ordenamiento jurídico colombiano de manera generalizado y con el apoyo del Estado como política para el posconflicto.

\section{DESARROLLO DEL TEMA}

Su estudio lleva en sí mismo disposiciones de otros contratos mercantiles o civiles, como similitudes con el arrendamiento de inmueble rural o con la sociedad, sin embargo, esta hipótesis ha sido muy debatida por la doctrina jurídica. Todo por la falta de normatividad especial sobre el contrato de aparcería, se ha regulado por uno u otro régimen normativo.

En el sistema jurídico colombiano el contrato de aparcería se encuentra reglamentado por la Ley 100 de 1944 y la Ley 06 de 1975 en la que determina las normas que se dicten y la forma de explotación de la tierra, así mismo en parte con el Código Civil frente a las reglas particulares de arrendamiento de predios rústicos con el Artículo 2041.

Presenta similitud con el contrato de arrendamiento, puesto que este último es de cambio o conmutativo, mientras el de aparcería es asociativo. El arrendamiento históricamente comenzó sobre pequeñas parcelas, mientras la aparcería se 
dio en gran medida para grandes capitales y patrimonios o, en su defecto, para pequeños espacios que no estaban siendo cultivados. Sin embargo, hay coincidencia en que las partes mantienen la responsabilidad de cuidar como buen padre de familia el inmueble para evitar todo tipo de usurpación o perturbación por parte de terceros. Del mismo modo, existe una protección ambiental a los bienes que contengan las características tales como bosques o árboles de conservación.

La aparcería participa con algunos elementos de la sociedad. La sociedad de capital e industria, sería la más cercana, ya que se utiliza por cada socio el aporte en capital y el aporte del trabajo, llamándose socios industriales. Estos responderían frente a sus ganancias o pérdidas obtenidas. La diferencia radica en quién sería el encargado de administrarla, ya que en la sociedad cualquier socio industrial podría hacerlo, mientras en la aparcería solamente el concedente o propietario mantendría su calidad de dueño y por ende de administrador y director técnico de su bien.

Simplificando y reduciendo a su mínima expresión las diferencias existentes entre la aparcería y la sociedad, podríamos decir que mientras en la aparcería el dador transfiere el uso y goce del bien dado en aparcería, en la sociedad el mismo es puesto en común para coadministrarlo y cogozarlo. Además, se diferencian en cuanto al objeto de reparto, pues mientras en la aparcería el mismo se constituye con los frutos, en la sociedad el mismo se conforma con los beneficios, término no equivalente al de "frutos". (Dotta Salgueiro, 2003, p. 10)

Así mismo se le ha atribuido como un contrato mixto, es decir, un contrato conjunto que tiene varias características en común con otros contratos, muy específicamente con el de arrendamiento o el de colonato, este último como forma de explotación de bienes rurales, sin embargo, esta figura desapareció y es particular por las limitaciones a la libertad propias que existieron en la Edad Media. No obstante, se deja a discusión los precedentes históricos que dieron vida al contrato de aparcería para analizar las distintas semejanzas y posibles raíces jurídicas que tendría de otros contratos.

Se cree una relación laboral entre el aparcero dador y el tomador, por el elemento de subordinación. Sin embargo, está claro que este tipo de contrato lo que hace es liberarse de muchas cargas frente a la contratación laboral de trabajadores agrícolas, por ser un contrato de carácter civil. No obstante, se debe estar siempre regulado por la ley que reglamente el contrato, para evadir las responsabilidades laborales como ha sucedido en otro tipo de contratos, por ejemplo, el de prestación de servicios, de igual modo, siempre primará la realidad sobre las formalidades al momento de cualquier discusión con el tema.

Por lo anterior, el Ministerio de la Protección Social frente al tema de la relación entre el contrato de aparcería y el derecho laboral, lo resalta y niega la existencia de un contrato de trabajo de la siguiente manera:

(...) Inicialmente podríamos considerar que elcontratode aparcería resulta ser un trabajo en compañía, donde una parte suministra unos medios de trabajo y la otra su esfuerzo físico, por lo que no podría ser considerado como un trabajo subordinado, al no existir un nexo laboral entre el socio propietario del terreno y el socio gestor (aparcero), sino que podría tratarse de una sociedad regulada por la normatividad civil o comercial según corresponda, pero en todo caso, no laboral. (Ministerio de la Protección Social, 2009)

\section{MARCO LEGAL DE LA APARCERÍA EN COLOMBIA}

Luego de la independencia y en la vida republicana, se presentaron varias leyes importantes para solucionar el problema del acceso y distribución de la tierra en Colombia. La Ley 48 de 1882, defiende al poseedor y trabajador de las tierras baldías: "Los cultivadores de los terrenos baldíos, establecidos en ellos con casa y labranza, serán considerados como poseedores de buena fe, y no podrán ser privados de la posesión sino por sentencia dictada en juicio civil ordinario" (Ley 48, 1882, art.2). 
Con la ley 74 de 1926, sobre fomento a la agricultura y a la inmigración, el Estado comienza a incentivar el uso de la tierra rural, promoviendo censos y estadísticas agrícolas, así mismo señaló sobre la división de la tierra, un gran problema que aquejaba a la sociedad del momento, dando como alternativa la subdivisión de grandes haciendas y la colonización agrícola. Del mismo modo, se promulgó estimular a los extranjeros que llegasen a vivir en Colombia, donde el Tesoro Público les destinaba unos auxilios para sus estadías.

La mencionada ley fue el antecedente para la promulgación de la ley 200 o Ley de Tierras de 1936, marcando una nueva idea sobre la posesión de las tierras que antes eran consideradas baldías, solo bastaba probar la propiedad privada por medio de "hechos positivos propios de dueño, como las plantaciones o sementeras, la ocupación con ganados y otros de igual significación económica" (Ley 200, 1936, art. 1). Los que no probasen estos elementos, serían considerados baldíos, con excepción de los bienes debidamente registrados.

La Ley 200 de 1936, promovida por el presidente Alfonso López Pumarejo, permitió la extinción de dominio de terrenos sin indicios de propiedad privada. Así al tercer año sin que se hubiese realizado actos de señor y dueño, la nación se reservaba la facultad de extinguir el derecho de dominio, situación similar con un predio inutilizado por un lapso de diez años.

Posteriormente se expide la Ley 100 de 1944 o Ley de Aparcería. Luego la Ley 135 de 1961, generando reformar a la normatividad anterior, debido a la violencia que azotaba al país, donde se expulsaron a pequeños aparceros, arrendatarios y jornaleros, por parte de grupos armados al margen de la ley. Por ello, la modernización trató de mitigar este problema. A pesar de la violencia y la implementación de trabajadores asalariados en las antiguas haciendas contratados por los propietarios, generó el desuso de la aparcería.

Ante lo anterior, el liberal Carlos Lleras Restrepo, da lugar a la Ley $1^{a}$ de 1968 , como una reforma a la Ley 135 de 1961. Manteniendo y reforzando lazos con los Estados Unidos en un solo modelo económico de industrialización por sustitución de importaciones. Para ello, ayudar y mejorar las condiciones higiénicas, sociales y comerciales de los campesinos fue una prioridad, con el fin de abrir mercados extranjeros. Favoreciendo en su mayoría a los aparceros y arrendatarios.

Con la llegada del conservador Misael Pastrana Borrero, pretende opacar las ideas revolucionarias liberales anteriores, por ello se expide la ley 4 y 5 de 1973, ayudando a los campesinos organizados y a los latifundistas. Fue el Pacto de Chicoral, en el Departamento del Tolima, una antesala de la normatividad mencionada, para solucionar los problemas dejados sobre la tierra de la Ley $1^{\mathrm{a}}$ de 1968. Posición contraria, para el escritor A1fredo Molano, citado por El Tiempo (2007):

Señala que tras el señalado pacto los dueños de las grandes haciendas pudieron reprimir por la fuerza el intento de los campesinos de invadir sus tierras. Y agrega que con el Pacto de Chicoral se clausuró el último de los grandes intentos por hacer una reforma agraria que favoreciera a los más pobres. (El Tiempo, 2007)

En el mismo sentido, el gobierno de Misael Pastrana Borrero promueve la Ley $5^{\mathrm{a}} \mathrm{de}$ 1973, por el cual se estimula la capitalización del sector agropecuario, con ayudas de fondos y créditos para empresarios del campo. Los plazos, periodos de gracia, tasas de interés, entre otros, fueron mecanismos incluidos en la ley para estimular la inversión agrícola.

Por último, el Decreto 2303 de 1989, por el cual el Presidente de la República, crea y organiza la jurisdicción agraria, determinando que estudiará los conflictos agrarios que "deriven de la propiedad, posesión y mera tenencia de predios agrarios, de las actividades agrarias de producción y de las conexas de transformación y enajenación de los productos" (Decreto 2303, 1989, art. 1), excluyendo los que originen actos mercantiles y 
relaciones laborales.

No obstante, este proceso de organización de la jurisdicción agraria, no ha tenido gran refuerzo legal, posteriormente con los cambios constitucionales que vivió el país, entra en vigencia la Ley 270 de 1996, por el cual se expide la Ley Estatutaria de la Administración de Justicia, afectando a los órganos jurisdiccionales agrarios. Así mismo, en la actualidad con la entrada de la Ley 1564 de 2012, por medio del cual se expide el Código General del Proceso, entrada en vigencia el 01 de enero de 2016, en el literal c) del artículo 626, especifica la derogación del Decreto 2303 de 1989, entre otros más.

\section{RESULTADOS}

Se determina que el contrato de aparcería contiene características generales al igual de otros contratos, tales como que sea bilateral, formal, oneroso, principal, nominado y típico, aleatorio y de libre discusión. Así mismo, contiene elementos esenciales de todo contrato, como es el consentimiento entre el aparcero y el propietario; la capacidad, porque se compromete el patrimonio, el interés y generaría responsabilidades; el objeto lícito y causa lícita.

Así mismo, se plasma que las reglas, cargas, beneficios y obligaciones en el contrato de aparcería, están fundamentadas en las leyes 100 de 1944 y 06 de 1975, donde la primera es considerada la que mayor profundizó la aparcería, y la última es la que rige en la actualidad.

\section{Desarrollo histórico}

Colombia como cualquier otro país de Latinoamérica conquistado y colonizado por el Imperio Español, llegó a importar el sentido de derecho dado en España frente al uso de la tierra, siendo de sumo valor la conservación y propiedad familiar, colocando la tierra bajo protección y uso exclusivo del núcleo familiar, para así cubrir necesidades de sustento diario. Esta figura jurídica, aún tiene relevancia en la cultura colombiana, al ser un prototipo de elemento familiar con un grado muy conservador.

Aquella sociedad feudal de tiempos coloniales y republicanos, fue la antesala de nuestra actual organización social, producto de ella hoy es la gran concentración de la tierra como el mayor problema agrario en el país, junto con una población campesina eminentemente conservadora y enemiga del cambio social. Cuando el desarrollo de las ciudades o cascos urbanos en Colombia obtuvieron el auge o boom del café, los textiles o los licores principalmente, de la mano con el desarrollo industrial, generó una comunicación comercial entre los pueblos y por ende dinamizó la economía.

Se parte de la conquista y la colonización, demostrando que el dominio estaba en el aborigen sobre las tierras, en Colombia los chibchas son un ejemplo de este reconocimiento. Hasta en 1512 cuando la Corona Española expide las Leyes de Burgos, declarando que las tierras conquistadas eran propiedad española, estableciendo al indio como vasallo libre y con derecho a la propiedad privada, pero como súbdito al Reino Español.

La propiedad privada surgió de tres maneras, la primera, fue el otorgamiento de la tierra por parte de los cabildos, providencia o ciudades construidas por los españoles, quienes le adjudicaban a sus colonos grandes extensiones de tierras bajo la figura de la encomienda, la segunda forma, fue a través de la auto adjudicación de un terreno conquistado, aquellos soldados y conquistadores se atribuían tierras como compensación de sus esfuerzos realizados y la tercera forma se hizo a través de la Real Audiencia, institución que otorgaba tierras y resolvía los conflictos territoriales.

En cuanto a la pequeña y mediana propiedad, se tiene que esta nació como consecuencia de la aniquilación de los hombres indios tributarios, el mestizaje de las indias con los españoles, la llegada de encomenderos peruanos derrotados por la Corona Españoles y la crisis de España de 1550. La primera de ella, fue la aniquilación de 
los indios por la explotación y malos tratos de los encomenderos en las mitas agrarias, mineras y domiciliarias en donde los indios hombres tributaban, tal es así, que "el balance de las nuevas conquistas fue desastroso, el número de tributarios indígenas, en el periodo 1563-1602, cayó un $68,2 \%$ en la zona oriental, pasando de 85.530 a 27.235" (Arango Restrepo, M., 2014, p.47).

La actividad económica de los españoles en el territorio colombiano, se basó en la minería y ganadería. Es así, que se vieron en la tarea de cultivar alimentos básicos para el abastecimiento de la población española. Los territorios de los indígenas, fueron propios para satisfacer la canasta familiar de los españoles pobres. Posteriormente, el aumento de los impuestos a los encomenderos, dio lugar a importar esclavos negros y hasta obtenerlos a crédito.

Por otro lado, los negros y afro descendientes, fueron la alternativa para evitar el empobrecimiento de los españoles. Su mano de obra producto de África, solventó gastos y acumuló riquezas. La minería y las plantaciones, generaban buenos recursos para la época. "En efecto, en el actual Santander había 51 trapiches en 1670, de los cuales 37 explotados con 560 esclavos, 6 con mano de obra familiar, 2 jornaleros blancos y mestizos y 4 sin información" (Arango Restrepo M., 2014, p. 61).

La Ley de Tierras fue muy importante para la solución de los conflictos agrarios que vivía el país en ese momento, se debe a una respuesta dada del comienzo de gobiernos liberales como el de Olaya Herrera y López Pumarejo, a la grave situación de conflictos jurídicos y sociales por la tenencia de la tierra, especialmente en las regiones de los Llanos Orientales, en Cundinamarca, Tolima, Huila y el Eje Cafetero.

El proceso de parcelación de haciendas, fue una alternativa y un alivio ante la violencia y toma a la fuerza de tierras por parte de campesinos, llevando al Gobierno Nacional a fraccionar las grandes haciendas. Muchas de ellas se realizaron de manera voluntaria por sus propietarios, "cuando enfrentaron los efectos combinados de hipotecas onerosas y presión campesina, algunos hacendados decidieron fraccionar. Reservaron para sí porciones más o menos considerables y la casa de la hacienda, y parcelaron el resto" (Palacios, Marco, 2011, p. 113).

La parcelación fue la solución por parte de los gobiernos liberales a los movimientos sociales presentados a comienzos del siglo $\mathrm{XX}$, inclusive recibió el apoyo conservador de la época, quienes juntos veían a las fuerzas extremas aliados del comunismo o socialismo internacional, incitando al descontento rural organizado y armado, aprovechados de las disputas entre arrendatarios, aparceros, colonos, hacendados e intermediarios.

Entre el proceso de fraccionamiento de grandes haciendas, el más representativo en la historia de la aparcería en Colombia, se dio en la Hacienda El Chocho, a la que corresponde la formación histórica de Silvania Cundinamarca, se debió a que invasores reclamaban la adjudicación de tierras y los propietarios se negaban a entregarlas, respaldados en sus títulos legalmente registrados. Ante ello, la Gobernación de Cundinamarca, en desarrollo de la ordenanza 35 de 1933, por medio de compraventa de la hacienda "el 21 de marzo se suscribió en la Notaría $3^{\circ}$ de Bogotá" (Palacios, M, 2011, p. 120).

Era tan fuerte el poder de la Hacienda El Chocho en Cundinamarca, que tenían su propio patriarca, el señor don Ángel María Caballero, además era un gran latifundista cafetero de la Región del Sumapáz. Su propia superestructura y autonomía, generó una revolución agraria interna que repercutió en las regiones aledañas y por ende en el Departamento de Cundinamarca, al respecto:

La hacienda, por el año 1930 tenía su propia moneda (el 'medio real) para las transacciones comerciales con los arrendatarios. Incluso, con esta se pagaba el café que se cosechaba en sus parcelas. Era tanta su autonomía que tenía un reglamento de trabajo propio. El Chocho, al desintegrarse en más de mil parcelas, se convirtió en símbolo de la revolución 
agraria, en el modelo de parcelaciones y en cuna del primer partido agrario. (González, K. 2002).

El café en el siglo XX fue un resultado exitoso de la parcelación. La región del Eje Cafetero en el país, hasta los años setenta se benefició de contratos agrarios como la aparcería, donde los nuevos caficultores, propietarios de minifundios aprovecharon la llegada de campesinos desempleados del Cauca, para explotar el campo por medio de cafetales y visionando un mercado liberal, comercial e industrial del "grano de oro" de Colombia.

El Gran o Viejo Caldas, el cual utilizó la figura de la aparcería en pequeños fundos, incentivando proyectos públicos, como la construcción de carreteras, acueductos, puestos de salud, escuelas y seguridad para sus campesinos cafeteros. Pues "Gracias al café, la nueva sociedad empieza a conocer los beneficios de un cultivo de pequeña superficie con alto efecto distributivo del ingreso, con un modo de producción capitalista, lo que tendrá validez hasta la década de 1970" (Duque Escobar, G., 2017, p. 6).

\section{La aparcería en otros países}

La aparcería en otros países, se resalta el éxito de las granjas agrícolas en Estados Unidos, por el cual los grandes terratenientes voluntariamente subdividieron sus tierras, buscando la participación de aparceros, donde obtenían para sus gastos básicos y pequeños privilegios. Jaynes, citado por Gaido (2000, p. 25), menciona que la aparcería en los Estados Unidos:

Fue generalmente adoptada debido a la incapacidad de los terratenientes de pagar salarios dentro de un periodo de tiempo razonable; es decir, porque la acumulación de capital en el sur no estaba lo suficientemente avanzada como para organizar la agricultura sobre bases capitalistas.

La división de las tierras en aparceras, desarrolló la producción y los propietarios tendían, sus vistas sobre tantas actividades, dando paso a la venta de terrenos y la adquisición de propieda- des de quienes no tenían pero la labraban. Esta es la esperanza que se le debe brindar al aparcero, el fin último de obtener dominio total de la tierra. En pocas palabras, la aparcería fue vista un peldaño que anticipaba la adquisición plena de la propiedad, dando paso a la formación de pequeños capitalistas agrarios.

Así mismo en México, con la Ley Federal del 23 de junio de 1920 o Ley de Tierras Ociosas, fue significativa para el uso de la aparcería con el apoyo del Estado, fijando extensiones máximas dependiendo de los climas y temporadas. Fue asignaciones de tierras con el objeto de su explotación, es decir, un mecanismo netamente productivista. Luego de una etapa revolucionaria comprendida desde 1910 a 1920. El Estado de Sinaloa, logró la aparcería con la llegada de extranjeros griegos a sembrar vegetales, verduras y cítricos.

Se retoma en Estados Unidos, la Ley de Granjeros entrada en vigencia en 1863, en el proceso de reconstrucción del país tras el fin de la Guerra Civil Norteamericana. Contribuyendo a cambios trascendentales en el tema agrario y la redistribución de la propiedad. Su nombre legal fue "Homestead Act o Ley de Asentamientos Rurales" (Álvarez, J., 2017) de 1862, impulsada por el presidente Abraham Lincoln, buscando la atracción de inmigrantes europeos y la colonización del oeste americano, ampliando las grandes tierras no habitadas para la época.

Su propuesta se debe a parcelar las grandes tierras improductivas, para luego obtener la titularidad del dominio. Incentivando al campesino o granjero, así como con innovaciones tecnológicas sobre las parcelas. Ante el tamaño de los predios, "se ordenó que un ciudadano o familia de Estados Unidos sólo pudiera ser propietario de un máximo de 64,7 hectáreas, agregando eventualmente una propiedad contigua a una primera hasta acumular como máximo dicho límite" (Montenegro Trujillo, I., 2010). 


\section{Aparcería en la actualidad colombiana}

En la actualidad colombiana, según cálculos entregados por la Unidad de Planificación Rural Agropecuaria (UPRA), entre las variadas modalidades contractuales agropecuarias, la aparcería se ubica en el tercer lugar, luego del arrendamiento, como principal opción contractual utilizada por el campesino colombiano y luego por el usufructo el cual genera un goce y uso del bien inmueble, pero con la finalidad de devolverlo.

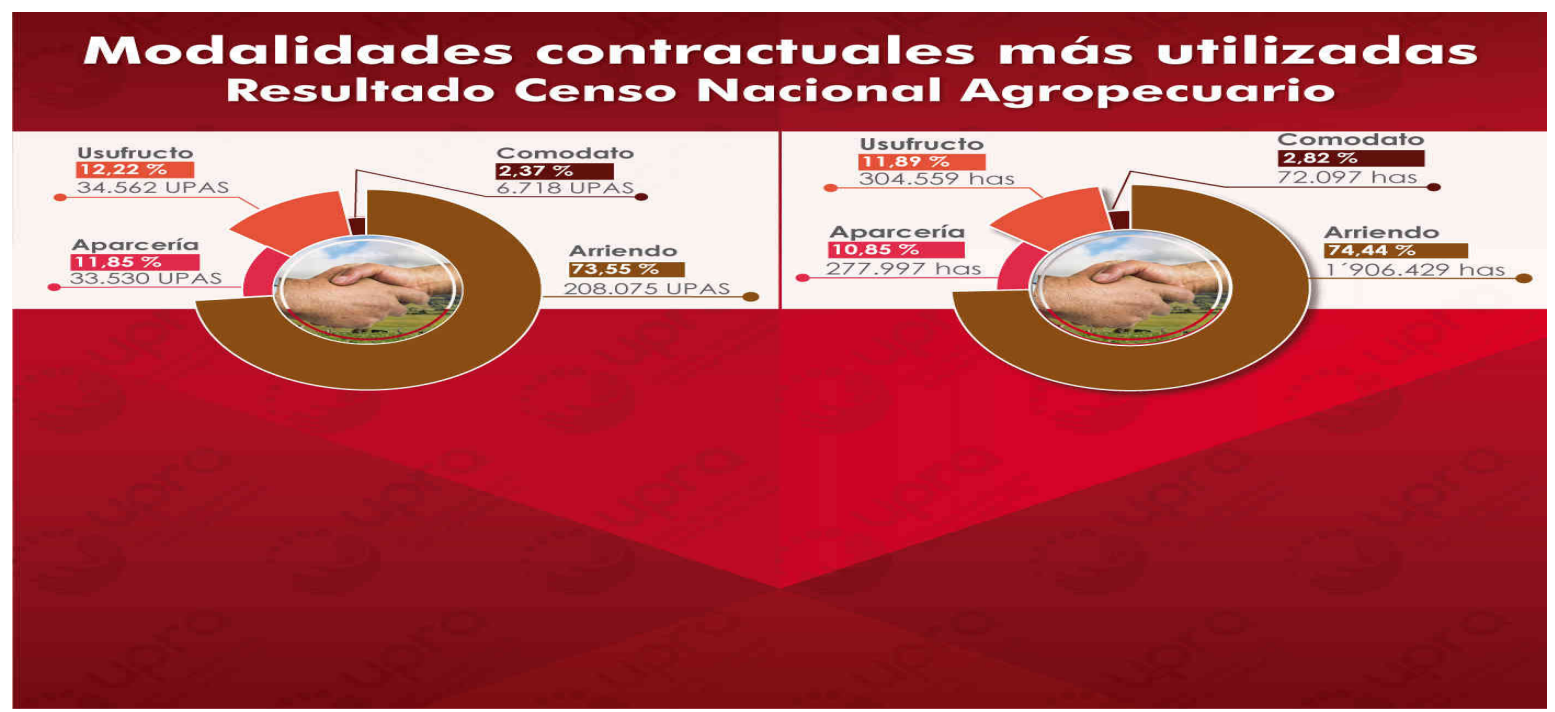

Figura 1. El 54.3\% de los predios rurales del país se explotan sin títulos de propiedad. (2017). Revista Dinero.

El resultado refleja el interés que en gran medida tienen los propietarios de bienes inmuebles rurales, ya que prefieren tener una renta, cumplir un favor o realizar una tarea, siendo ajenos los propietarios para invertir en un negocio agrario. Pues es la aparcería, donde necesita la participación del propietario, empresario o terrateniente, para invertir en un negocio asumiendo sus pérdidas.

Un caso presente sobre restitución de tierras, se realizó en el Departamento de Antioquia, por el cual una sentencia jurídica superó una incertidumbre sobre la posesión de una tierra, donde ocho (8) familias vivieron, crecieron y cultivaron la tierra, pero por ocupación por aparcería hace sesenta años. Sus descendencias, crearon sindicatos agrarios y produjeron los terrenos.

Fue gracias al gobierno y la gestión de Juan Manuel Santos, por el cual la vereda San Antonio obtuvo la titularidad de varios predios, luego de estar truncados por presencia de grupos al margen de la ley. Al respecto:
El desplazamiento forzado empezó a mediados de los 90 y se agudizó con la presencia de paramilitares de los bloques Metro y Héroes de Granada. Debido a esto, muy pocos parceleros lograron legalizar su calidad jurídica sobre la finca San Antonio, que ahora es conocida como una vereda del corregimiento Cristales. (Caracol Radio, 2018).

Con la minería se ha logrado parcelar algunas haciendas a favor de los campesinos o cultivadores pequeños. Es el caso del bajo Cauca en el Departamento de Antioquia, donde Luis cambió de vivir en una casa pequeña de seis metros cuadrados, a obtener una casa de 150 metros, con la ayuda de una empresa minera denominada Mineros S.A. que se la otorgó, con apoyo del Incoder.

Este proceso se obtuvo por fases, primero cumpliendo a cabalidad el contrato de aparcería, luego en un comodato y por último, la obtención de la escritura de la propiedad.

Desde hace 10 años, los interesados pueden participar en una convocatoria para tener un contrato de aparcería, a cambio de cultivar 
terrenos donde hubo una explotación mine-

ra. Personas como Luis cumplieron el contrato por tres años, luego pasaron a la figura de comodato y, a los 6 años de habitar el predio, recibieron la escritura. (Escobar, M., 2016)

El anterior es un ejemplo preciso sobre los beneficios del contrato de aparcería en la actualidad colombiana. Donde un señor, pasa de trabajar en una minería ilegal, a aplicar en un contrato de aparcería y logrando su adquisición del predio, como fin último de la aparcería, cumpliendo un beneficio social de la propiedad.

En palabras del señor Luis, citado por Escobar, M. (2016) sostiene: "Ahora estamos muy amañados. Yo trabajo, reposo, estoy con los niños, trabajo, vuelvo y reposo, vendo lo que cultivo en el pueblo y en cada venta no saco menos de cien mil. Vivimos tranquilos, trabajando bien y sin angustias" (Escobar, M., 2016).

Otro caso de parcelación en Colombia, se encuentra en la Hacienda Misiones ubicada en el municipio del Colegio, en Cundinamarca, depende de la actividad agrícola, en productos como los mangos, cítricos y café, del mismo modo la ganadería. Esta finca tenía alrededor de 400 empleados. Recolectores que llegaban de regiones como el Tolima o Caldas. Ayudándoles a sus familias con educación a sus hijos y el mejoramiento de viviendas a los trabajadores.

Sin embargo, para el año 2006 se inició un proceso de parcelación sobre la hacienda, debido a la escasez para cumplir con las obligaciones laborales, se decide disminuir el número a 18 trabajadores, para ello el contrato de aparcería fue efectivo.

Para el año 2006, se inició un programa dentro de la Hacienda de eliminación y sustitución del café por pasto, se eliminaron entre el 2006 y el 2008, 300 hectáreas de café, a su vez quedaron en nómina 18 trabajadores, los cuales siguen viviendo en la Hacienda, en casas que se les han asignado, el contrato es de aparcería y en algunas ocasiones se hace al jornal dependiendo la labor que se necesite realizar.
(Gómez Pinzón, J. H., 2011, p. 11)

A través de la aparcería, por su carácter asociativo y de colaboración, sirve para la entrega de tenencia de las tierras de la Hacienda Misiones, para explotarla y repartir sus utilidades o frutos. Al aparcero, se le otorgaba una vivienda donde tenía el derecho de cultivar a su libre disposición, siempre que cumpliera con las tareas agrícolas de la hacienda.

En una comparación de los años 2006 y 2008, se demuestra que el contrato de aparcería en la Hacienda Misiones fue la más productiva frente a los otros trabajadores, tales como jornaleros, empleados directos y al destajo.

La vinculación a los trabajadores se divide en empleados de nómina y empleados por jornal, los empleados por nómina están con un contrato de aparcería, y los demás, que se contratan para alguna labor de recolección o trabajos específicos. Para el año 2008, se contaban con 18 trabajadores de planta, el resto de trabajadores que llegaba a unos 15 más eran contratados al jornal, que se paga solo por la actividad diaria que se necesite realizar. (Gómez Pinzón, J. H., 2011, p. 77)

Por otra parte, se presenta que los nuevos propietarios de las parcelas otorgadas luego de liquidar o subdividir la histórica Hacienda Misiones, sufrieron el desgaste que padecen miles de campesinos al obtener una tierra propia, el cual es la falta de incentivos para producirla. Quedando rezagados a buscar fuentes de ingresos, donde su labor sea prestando servicios físicos en actividades agrarias.

Por último, se espera que la aparcería sirva de sustento en la sociedad colombiana luego del Acuerdo Final para la Terminación del Conflicto y la Construcción de una Paz Estable y Duradera, entre el Gobierno y las FARC. En el punto uno se señala que, a través del Fondo de Tierra para la Reforma Integral, se distribuirán tres millones (3.000.000) de hectáreas durante los primeros diez (10) años. En Colombia la población víctima del conflicto, era para el año dos mil catorce 
(2014), de alrededor de seis millones registrados, cifra que ha ido acrecentando, para tener en el "año dos mil diecisiete (2017) un total de ocho millones quinientos cincuenta y cuatro mil seiscientos treinta y nueve (8.554.639)" (RUV, 2017).

Se puede indicar, que aquellas millones de hectáreas son insuficientes para satisfacer a la población desplazada, así mismo, que la entrega o el proceso de adjudicación de las tierras por parte del Fondo de Tierra para la Reforma Integral a favor de la población desplazada, tiene que respetar los parámetros de la Unidad Agrícola Familiar (UAF) de cada municipio, esto quiere decir que el municipio deberá entregar las hectáreas mínimas establecidas para la sobrevivencia de una familia campesina.

Otro punto en el posconflicto, es la lucha contra la pobreza extrema y la superación del hambre. Colombia es uno de los países con mayor pobreza extrema en la región latinoamericana, se debe por la no satisfacción de la alimentación.

Ante los anteriores puntos, la aparcería se impone como una oportunidad de productividad, ya que al mismo tiempo se pueden cultivar frutas, hortalizas, vegetales y verduras que calmarían el hambre al aparcero y su familia, es decir, la agricultura de pancoger, hoy hecha una tragedia por la ausencia de la aparcería. Será necesario trabajar de la mano entre el Estado y los grandes propietarios rurales, para subdividir las tierras y comenzarlas a producir, para dar paso progresivo y transitorio al acceso pleno del derecho de dominio sobre el campesino víctima de la violencia colombiana.

\section{CONCLUSIONES}

El contrato de aparcería se puede estipular como la relación jurídica contractual en la cual una de las partes, denominada propietario cede el uso de la tierra o con objetos muebles para que un aparcero, sujeto que tiene los conocimientos técnicos, pero no los recursos económicos, la destine a la producción agrícola o ganadera; actividad que tiene por finalidad la repartición de utilidades o perdidas en sociedad por los contratantes.

Cabe destacar que dicha figura jurídica, se encuentra actualmente en Colombia en desuso y ha sido reemplazada paulatinamente por el contrato de arrendamiento rústico, esto motivado por dos factores, el primero es que el dueño de la parcela tiene garantizado sus ganancias con el simple hecho de arrendarlas, no tiene ánimo societario ni le interesa el reparto de utilidades y la segunda es que durante la mitad del siglo XX, el abuso del derecho hizo del mismo, un medio jurídico de explotación al campesinado, a través del fraude al contrato de trabajo, agudizando la exclusión social, la pobreza y los conflictos agrarios por la tenencia de la tierra.

A pesar de ello y sin ser indiferentes a los antecedentes presentados, al realizar un análisis profundo en cuanto a las ventajas y los elementos esenciales del negocio jurídico, se puede deducir que el contrato de aparcería es la relación jurídica contractual más idónea y pertinente para el momento histórico que vive el país.

De esta manera, ante el Acuerdo de la Habana que parece inmodificable a pesar de lo que llegare a suceder en la presidenciales de mayo del año en curso y la necesidad del gobierno de aterrizar e implementar con prontitud lo pactado con las FARC a la realidad, surge el contrato de aparcería como la fórmula transitoria para la superación a los desafíos y tropiezos en cuanto a la concertación y realización de los objetivos enmarcados y enunciados en el tema agrario del Acuerdo Final.

A raíz de lo dicho, se tiene que frente al primer punto del Acuerdo Final para la Terminación del Conflicto y la Construcción de una Paz Estable y Duradera, que el gobierno determinó los principios para la transformación de las políticas públicas dirigidas al sector agropecuario, todas ellas orientadas a una Reforma Rural Integral, en el que se resalta el valor de la familia campesina, se otorga importancia al papel de la mujer cabeza de hogar del sector rural, se recalca el derecho 
fundamental del acceso a la tierra que tiene el campesino y la obligación por parte del Estado en la prestación de los servicios esenciales en los territorios rurales que conlleve a la realización de una vida digna de sus habitantes.

Por consiguiente, se fijó la creación de la Agencia Nacional de Tierras (ANT) decreto 2365 del 2015, Agencia Desarrollo Rural (ADR) decreto 2364 del 2015, Agencia para la Renovación del Territorio (ART) decreto 2096 del 2016, Consejo Superior del Uso del Suelo decreto 2367 de 2015, Consejo Superior de Restitución de Tierra con el decreto 2368 del 2015 y la Dirección de la Mujer Rural con el decreto 2369 de 2015; entidades que entraron a suplir las funciones del INCODER y están orientados exclusivamente a la transformación del campo en concordancia con el Acuerdo Final.

En cuanto a la tenencia, bautizada en el acuerdo como la democratización de la tierra, el gobierno planteó una meta de tres millones de hectáreas para un periodo de doce años, la cual sería repartidas para sujetos que cumplan a cabalidad los requisitos del articulo 4 y 5 del decreto 902 del 2017, parcelas que obtendrá el Fondo de Tierras a través de la extinción de dominio, la expropiación, los procesos de recuperación de tierras baldías en tenencia de particulares y de la adjudicación de baldíos.

El uso de la extinción de dominio por el no cumplimiento de la función social y ecológica de la propiedad y el tema de la expropiación por motivos de interés social e utilidad pública no cayó muy bien dentro de las altas esferas de la sociedad, su ambigüedad y generalidad da oportunidad a diversas interpretaciones, que hacen más dificultoso la aceptación y la materialización de lo acordado con las FARC por parte de la sociedad.

Es por ello, que el contrato de aparcería es un medio jurídico transitorio y eficaz para la implementación de la Reforma Rural Integral, en tanto que posibilita a la Agencia Nacional de Tierras recaudar las 3 millones hectáreas, con la voluntad contractual de los propietarios de las tierras en desuso, mientras que se da cumplimiento con la dignificación del campesino, el resurgimiento de la industria agrícola y el aumento de los movimientos financieros para el mejoramiento de las condiciones de vida sin que se cree un caos y una incertidumbre jurídica.

El contrato de aparcería confiere seguridad jurídica a los grandes hacendados, en el sentido en que no se vulnera sus derechos fundamentales a la propiedad privada, por lo que seguirán siendo dueños de sus parcelas, mientras que ceden el uso de su propiedad a campesinos o aparceros, que se ocuparan de producir económicamente dichas tierras que no se encuentran cumpliendo su función social. Cabe aclarar, que al señalar de ceder el uso de la propiedad, es entregar la titularidad del dominio luego de obtener una justa retribución económica del valor de su tierra, en el que interviene el Estado como garante de este proceso.

En otras palabras, surge una asociación entre el campesino (aparcero) y el propietario de la tierra para la industrialización del campo colombiano, en virtud a una complementación, el primero de ellos cuenta con los conocimientos técnicos para destinar el bien inmueble o mueble para una producción agrícola o ganadera, el segundo tiene los recursos económicos para financiar proyectos que sean viables tanto financieramente como ambientalmente, asociación que contribuirá al resurgimiento del agro y de la ganadería, progreso que se verá a través del mejoramiento de las condiciones de vida de la familia campesina, de los movimientos financieros y la reactivación del comercio en los pueblos alejados de las grandes urbes.

Por otra parte, la expropiación es una herramienta jurídica muy agresiva que en vez de apaciguar los ánimos, crea más odio y resentimiento, agudizando el conflicto agrario que origino una guerra por más de cincuenta años, afirmación que se encuentra fundamentada en que desde la 
colonización antioqueña acaecida en 1820 hasta la reforma rural de 1936, siempre se ha hablado de la utilización de la expropiación para los predios que no cumplen su función social y nunca se ha logrado una transformación radical en las políticas públicas en el campo, manteniéndose la desigualdad y la brecha entre lo rural y lo urbano.

Otra de las ventajas que aporta el contrato de aparcería para la implementación de la Reforma Rural Integral, es que el mismo permite la dignificación del ser humano y la materialización del principio de reparación integral, en cuanto a que las personas desplazadas que se encuentran en un estado de marginalidad y son sujetos de especial protección constitucional, puedan regresar a una situación similar antes de verse obligadas a abandonar su hogar, teniendo derecho a gozar de un bien inmueble, realizando actividades económicas propias del campo antes de que el acto $\mathrm{u}$ hecho generador de violencia les haya arrebatado su estilo y forma de vida.

Se puede hablar de dignificación de las condiciones de vida huma siempre y cuando la población desplazada pueda regresar a una situación similar antes de verse afectado por el daño antijurídico, sin tener que esperar durante más de diez o doce años para que el Fondo de Tierra le adjudique el bien inmueble definitivo.
A ello se estima según los datos del Registro Único de Victima, la población desplazada trasciende en la actualidad a más de unos ocho millones de personas y que la tierra prometida para la Reforma Rural Integral vendría siendo insuficiente para reparar ni siquiera a la mitad, de dicha grupo poblacional que se encuentra en estado de marginalidad.

Con el contrato de aparcería se vendría a cumplir parcialmente el principio de reparación, reintegrándolo en la sociedad, valorándole como sujeto de derecho y reactivando la economía agropecuaria que al país tanta falta le hace. Cumpliendo su total reparación, cuando supere los requisitos y términos adecuados y establecidos por el Gobierno Nacional, dando lugar a la obtención de la propiedad rural al campesino aparcero.

Por ello, el contrato de aparcería es la figura jurídica ideal para la transición y la implementación de la Reforma Rural Integral, pues sus elementos esenciales y las ventajas que podría conllevar a su debida y adecuada utilización, conllevará al progreso agropecuario de manera estable y progresiva, reivindicando a la población desplazada, manteniendo la fe en los ciudadanos que quieren y desean ver un país en paz, con equidad y en un desarrollo sostenible.

\section{REFERENCIAS}

1. Álvarez, Jorge. (2017). Homestead Act, la ley promulgada por Lincoln que daba tierras a los inmigrantes para colonizar el Oeste americano. Disponible en: https://www.labrujulaverde.com/2017/02/ homestead-act-la-ley-promulgada-por-lincoln-que-daba-tierras-a-los-inmigrantes-para-colonizar-eloeste-americano Consultado: Enero de 2018.

2. Arango Restrepo, Mariano. (2014). La tierra en la historia de Colombia. Bogotá, Colombia: Academia Colombiana de Ciencias Económicas.

3. Caracol Radio. (2018). Juez de restitución devolvió 15 predios a campesinos de San Roque. Disponible en: http://caracol.com.co/emisora/2018/02/20/medellin/1519152565_346091.html Consultado: Febrero de 2018.

4. Congreso de Colombia. (30 de noviembre de 1926). Sobre fomento a la agricultura y a la inmigración y se dictan otras disposiciones. (Ley 74 de 1926). DO: 20361. Disponible en: http://www.suin-juriscol. gov.co/viewDocument.asp?id=1622221 Consultado: Febrero de 2018.

5. Congreso de Colombia. (30 de diciembre de 1936). Sobre Régimen de Tierras. (Ley 200 de 1936). DO: 23388. Disponible en: https://www.redjurista.com/Documents/ley_200_de_1936_congreso_de_la_republica.aspx\#/ Consultado: Noviembre de 2017.

6. Congreso de Colombia. (31 de diciembre de 1944). Sobre régimen de tierras. (Ley 100 de 1944). DO: 25759. Disponible en: http://www.suin-juriscol.gov.co/viewDocument.asp?id=1635845 Consultado: 
Febrero de 2018.

7. Congreso de Colombia. (15 de diciembre de 1961). Sobre reforma social agraria. (Ley 135 de 1961). DO: 30691. Disponible en: http://www.suin.gov.co/viewDocument.asp?id=1792699 Consultado: Enero de 2018.

8. Congreso de Colombia. (26 de enero de 1968). Por la cual se introducen modificaciones a la Ley 135 de 1961 sobre Reforma Social Agraria. (Ley 1 a de 1968). DO: 32428. Disponible en: http://www.suinjuriscol.gov.co/viewDocument.asp?id=1786063 Consultado: Enero de 2018.

9. Congreso de Colombia. (29 de marzo de 1973). Por la cual se estimula la capitalización del sector agropecuario y se dictan disposiciones sobre Títulos de Fomento Agropecuario, Fondo Financiero Agropecuario, Fondos Ganaderos, Prenda Agraria, Banco Ganadero, Asistencia Técnica, autorizaciones a la Banca Comercial, deducciones y exenciones tributarias y otras materias. (Ley $5^{\text {a }}$ de 1973). DO: 33828. Disponible en: http://www.suin-juriscol.gov.co/viewDocument.asp?id=1560157 Consultado: Febrero de 2018.

10. Congreso de Colombia. (10 de enero de 1975). Normas sobre contratos de aparcería y formas de explotación. (Ley 06 de 1975). Disponible en: http://www.sac.org.co/es/ambito-juridico/leyes/97-no006-de-1975-normas-sobre-contratos-de-aparceria-y-formas.html Consultado: Mayo de 2017.

11. Congreso de Colombia. (07 de octubre de 1989). Por el cual se crea y organiza la jurisdicción agraria. (Decreto 2303 de 1989). DO: 39013. Disponible en: http:/www.creg.gov.co/html/Ncompila/htdocs/ Documentos/Energia/docs/decreto_2303_1989.htm Consultado: Febrero de 2018.

12. Congreso de Colombia. (07 de marzo de 1996). Estatutaria de la Administración de Justicia. (Ley 270 de 1996). DO: 42745. Disponible en: http://www.secretariasenado.gov.co/senado/basedoc/ ley_0270_1996_pr004.html\#202 Consultado: Febrero de 2018.

13. Dinero. (2017). E1 54.3\% de los predios rurales del país se explotan sin títulos de propiedad. (Figura 1). Disponible en: http://www.dinero.com/pais/articulo/informalidad-en-el-campo-colombiano-unidadplanificacion-rural/248010 Consultado: Septiembre de 2017.

14. Dotta Salgueiro, M. (2003). El contrato de aparcería. Disponible en: http://wold.fder.edu.uy/agrario/ monografias/aparceria_dotta_2003.pdf Consultado: Mayo de 2017.

15. Duque Escobar, Gonzalo. (2017). Eje Cafetero: Construcción Social e Histórica del Territorio. Disponible en: http://www.bdigital.unal.edu.co/58401/1/ejecafetero-construccionsocialehistoricadelterritorio.pdf Consultado: Diciembre de 2017.

16. El Congreso de los Estados Unidos de Colombia. (28 de agosto de 1882). Sobre tierras baldías. (Ley 48 de 1882). DO: 5457. Disponible en: http://www.suin-juriscol.gov.co/clp/contenidos.dll/ Leyes/30019427?fn=document-frame.htm\$f=templates\$3.0 Consultado: Agosto 2017.

17. El Tiempo. (2007). Como un escenario de sucesos trascendentales en el país es recordado el corregimiento de Chicoral. Disponible en: http://www.eltiempo.com/archivo/documento/CMS-3587136 Consultado: Febrero de 2018.

18. Escobar, Melba. (2016). El Tiempo. El gigante invisible de la minería ilegal. Disponible en: http:// www.eltiempo.com/archivo/documento/CMS-16720622 Consultado: Marzo de 2018.

19. Gaido, Daniel. (2000). Un análisis materialista de la esclavitud y la aparcería en el Sur de Estados Unidos. Disponible en: http://www.academia.edu/5887987/Un_an\%C3\%A1lisis_materialista_de_ la_esclavitud_y_la_aparcer\%C3\%ADa_en_el_Sur_de_Estados_Unidos Consultado: Septiembre de 2017.

20. Gómez Pinzón, Johnny Harold. (2011). Impacto Socioeconómico De La Sustitución De Cultivos Agrícolas Sobre Los Trabajadores De La Hacienda Misiones Del Municipio El Colegio En Cundinamarca. (Trabajo de grado, Pontificia Universidad Javeriana). Disponible en: https://repository.javeriana.edu. co/bitstream/handle/10554/1667/GomezPinzonJohnnyHarold2011.pdf?sequence=1 Consultado: Enero de 2018.

21. González, K. (2002). Silvania, el refugio de los sutagaos. El Tiempo. Disponible en: http://www.eltiempo.com/archivo/documento/MAM-1367434 Consultado: Septiembre de 2017.

22. Ministerio de la Protección Social. (08 de enero de 2009). Concepto 5320. Disponible en: https://www. cijuf.org.co/conceptosminproteccion/2009/enero/c5320.htm Consultado: Mayo de 2017.

23. Montenegro Trujillo, Iván. (2010). Ley de tierras: expectativas y oportunidades. Disponible en: https:// razonpublica.com/index.php/conflicto-drogas-y-paz-temas-30/1469-ley-de-tierras-expectativas-yoportunidades.html Consultado: Enero de 2018.

24. Palacios, M. (2011). ¿De quién es la tierra? Propiedad, politización y protesta campesina en la década de 1930. Bogotá, Colombia: Fondo de Cultura Económica. 
25. Registro Único de Víctima (RUV). (2017). Total Nacional. Disponible en: https://rni.unidadvictimas. gov.co/RUV Consultado: Octubre de 2017.

26. Zulueta, M. M. (1949). El contrato de aparcería. Disponible en: http://www.mapama.gob.es/ministerio/ pags/biblioteca/hojas/hd_1949_12.pdf Consultado: Abril de 2017. 